\title{
Influence of sputtering atmosphere on hopping conductance in granular nanocomposite $(\mathrm{FeCoZr})_{x}\left(\mathrm{Al}_{2} \mathrm{O}_{3}\right)_{1-x}$ films
}

\author{
I. Svito $^{\text {a }}$, J.A. Fedotova ${ }^{b}$, M. Milosavljević ${ }^{c}$, P. Zhukowski $^{d}$, T.N. Koltunowicz $^{\text {d,* }}$, A. Saad ${ }^{\mathrm{e}}$, K. Kierczynski ${ }^{\mathrm{d}}$, \\ A.K. Fedotov ${ }^{\text {a }}$
}

a Belarusian State University, 220030 Minsk, Belarus

${ }^{\mathrm{b}}$ National Center for Particles and High Energy Physics of BSU, 220040 Minsk, Belarus

${ }^{\mathrm{C}}$ VINČA Institute of Nuclear Sciences, Belgrade University, 11001 Belgrade, Serbia

${ }^{\mathrm{d}}$ Lublin University of Technology, 20-618 Lublin, Poland

e Al Balqa Applied University, Physics Department, P.O. Box 4545, Amman 11953, Jordan

\section{A R T I C L E I N F O}

Article history:

Available online $\mathrm{xxxx}$

\section{Keywords:}

Electronic transport

Nanocomposites

Percolation

\begin{abstract}
A B S T R A C T
The present paper investigates conductivity $\sigma$ for a wide temperature range of $2 \mathrm{~K}<T<300 \mathrm{~K}$ in the nanocomposite $(\mathrm{FeCoZr})_{x}\left(\mathrm{Al}_{2} \mathrm{O}_{3}\right)_{1-x}$ films $(1-6 \mu \mathrm{m}$ thicknesses, $0.30<x<1.00)$ which were sputtered on glass-ceramic substrates from the compound target in vacuum chamber filled with $\mathrm{Ar}$ (set 1 films) or $\mathrm{Ar}+\mathrm{O}_{2}$ gas mixture (set 2 films). TEM and HRTEM images revealed that granular films of set 1 containing nanosized crystalline metallic bcc $\alpha$-FeCo-based nanoparticles embedded in the amorphous $\mathrm{Al}_{2} \mathrm{O}_{3}$ matrix. In case of $\mathrm{Ar}+\mathrm{O}$ atmosphere of deposited $\alpha$-FeCo-based crystalline "cores" with stabilized sizes were covered with an amorphous FeCo-based oxide "shells". The $\sigma(T)$ dependences were found to be in agreement with this phase structure. They show transition of the set 1 films $\sigma(T)$ curves with $x$ from tunneling (hopping) behavior below the percolation threshold $x<x_{\mathrm{C}} \approx 0.46$ to metallic one for $x>x_{\mathrm{C}}$. Moreover, as opposed to such behavior, for the set 2 films hopping mechanism of $\sigma(T)$ was revealed far beyond $x_{\mathrm{C}}$ due to the formation of semiconducting FeCo-based oxide "shells" separating electrically contacting FeCoZr cores.
\end{abstract}

(c) 2013 Elsevier B.V. All rights reserved.

\section{Introduction}

Composite materials consisting of ferromagnetic nanoparticles embedded in a dielectric matrix have occupied one of the center places in physics research at present time because of challenges regarding the theoretical understanding and practical applications [1]. There are two reasons for this interest: the tendency to miniaturization and improving of electronic magnetic devices performance [2] and the lack of understanding regarding the low-temperature carrier transport mechanisms in many of metal-dielectric composites, when dimensions of metallic phase particles are approaching nanometer scale.

The character of their DC/AC carrier transport should be strongly dependent on the composition of the material, and in particular, on the percolation threshold $x_{\mathrm{C}}$. The latter is determined by atomic fraction of metallic phase $x$ in composite, ratio $R_{\mathrm{m}} / R_{\mathrm{d}}$ metallic to dielectric phases conductances, and also some other parameters (the presence of native oxides of metallic nanoparticles

* Corresponding author. Address: Lublin University of Technology, 38a Nadbystrzycka Str., 20-618 Lublin, Poland. Tel.: +48 602730929; fax: +48 81 5384575.

E-mail address: t.koltunowicz@pollub.pl (T.N. Koltunowicz).
(MNPs), and also dimensions, shape and topology of MNPs distribution) [2-7]. In accordance with the percolation theory for binary composites [8], at $x<x_{\mathrm{C}}$ continuous current-conducting (or percolating) cluster cannot be formed, so that carrier transport is carried out by their tunneling from particle to particle through dielectric strata. therefore form continuous current-conducting clusters that will shunt the dielectric phase However beyond the percolation threshold $x>x_{\mathrm{C}}$, these particles can be in contact each other and shifting the composite on metallic side of insulator-metal transition (IMT). Moreover, for an appropriate interpretation of behavior of the electrical properties of many composite materials, during their preparation, the influence of the residual or specially added oxygen in a gas mixture at their preparation should be taken into consideration: the latter can result in the formation of oxide "shells" or precipitates at the interface between MNPs and dielectric matrix making structure of the composites more complicated and could strongly change their properties.

So, the present paper is devoted to the comparison of the low temperature dependences of DC conductivity in $\left(\mathrm{CO}_{0.45} \mathrm{Fe}_{0.45} \mathrm{Zr}_{0.10}\right)$ ${ }_{x}\left(\mathrm{Al}_{2} \mathrm{O}_{3}\right)_{1-x}$ nanocomposites, deposited in $\mathrm{Ar}$ and $\mathrm{Ar}+\mathrm{O}_{2}$ atmospheres, depending on phase structure and concentration of the alloy MNPs embedded into amorphous aluminum oxide matrix. 


\section{Experimental procedures}

The $\left(\mathrm{Co}_{0.45} \mathrm{Fe}_{0.45} \mathrm{Zr}_{0.10}\right)_{x}\left(\mathrm{Al}_{2} \mathrm{O}_{3}\right)_{1-x}$ thin film MNPs were fabricated by DC ion sputtering of the compound target onto the motionless glass ceramic substrate $(5 \mathrm{~cm} \times 25 \mathrm{~cm})$, using $2 \mathrm{keV}$ argon ion gun, at the rate of $0.28 \mathrm{~nm} \mathrm{~s}^{-1}$. The sputtered targets were composed of $\mathrm{Fe}_{0.45} \mathrm{C}_{0.45} \mathrm{Zr}_{0.10}$ alloy plates, covered with strips of amorphous $\mathrm{Al}_{2} \mathrm{O}_{3}$ that were pasted on top. The deposition was made in a vacuum chamber evacuated down to $1 \times 10^{-4} \mathrm{~Pa}$ and then filled with either pure argon up to total gas pressure of (6.7-9.6) $\times 10^{-2} \mathrm{~Pa}$ (set 1 samples) or with $\mathrm{Ar}+\mathrm{O}_{2}$ gas mixture with total pressure of $26 \times 10^{-4} \mathrm{~Pa}$ and partial pressures of argon $P_{\mathrm{Ar}}=67 \times 10^{-2} \mathrm{~Pa}$ and oxygen $P_{\mathrm{O}}=42 \times 10^{-3} \mathrm{~Pa}$ [7]. In this way, changing the area coverage by matrix stripes, the metal-to-insulator ratio in the deposited films could be varied along the substrate [7]. The films of set 1 with $0.28<x<1.00$ and thicknesses $d=(1-$ 4) $\mu \mathrm{m}$ and of set 2 with $0.31<x<0.64$ and thicknesses $d=(3-5) \mu \mathrm{m}$ were studied.

Structure and composition of the as-deposited granular films were studied (see, $[6,7])$, using the LEO 1455VP scanning electron microscope (SEM) with a special energy dispersive X-ray (EDX) microprobe, X-ray Empyrean PANalytical diffractometer (XRD), Mössbauer spectrometer MS2000 with ${ }^{57} \mathrm{Fe} / \mathrm{Rh}$ source and Rutherford backscattering spectrometry (RBS). Microstructure studies with electron diffraction (SAED) were also done using Philips EM400T transmission electron microscope (TEM), operated at $120 \mathrm{kV}$, and Philips CM200 operated at $200 \mathrm{kV}$ for high resolution analysis (HRTEM). EDX SEM and RBS measurements, allowed checking the samples' stoichiometry with an accuracy of $\sim 1 \%$, confirming $x$ and $\mathrm{Fe} / \mathrm{Co} / \mathrm{Zr}$ relation to be close to the nominal [7]. XANES and EXAFS measurements were performed at a beam line ID26 of the European Synchrotron Radiation Facility using high energy resolution fluorescence detection (HERFD) [7,9]. Thicknesses of the films were measured using SEM with an accuracy of $\sim 2-3 \%$ on cleavages of the samples studied.

For the electrical measurements the nanocomposite films were cut into rectangular strips with dimensions of $10 \mathrm{~mm} \times 2 \mathrm{~mm} \times d \mu \mathrm{m}$, and 4 indium contacts were made by ultrasound soldering. These samples were tested for 4-probe DC conductivity $\sigma$ measurements at low electric field intensities of $E<10^{5} \mathrm{~V} / \mathrm{m}$ while $I-V$ characteristics practically linear. The conductivity $\sigma$ versus temperature was measured (between 2 and $300 \mathrm{~K}$ ) using a closed-cycle cryogen-free cryostat system (Cryogenic Ltd., London). The PC based control using Lakeshore Temperature Controller (Model 331) allowed scanning the temperature with a rate of about $0.1-1 \mathrm{~K} / \mathrm{min}$ and to stabilize it (if necessary) with accuracy of $0.005 \mathrm{~K}$. The relative error of the conductance measurements was less than $0.1 \%$.

\section{Results and discussion}

The comparison of SEM, XRD, TEM, HTREM, SAED, EXAFS, XANES and Mössbauer data for the studied samples of sets 1 and 2 , presented in [7], drawing the following conclusions concerning their phase structure where Mössbauer and also magnetization studies were evident of a strong correlation between magnetic state and concentration of metallic fraction in the composites of set 1 : the samples with $x<0.43-0.45$ are in superparamagnetic state whereas with higher $x$ values they show ferromagnetic behavior [6,7]. Therefore the concentration of the order of $0.43-0.45$ can be interpreted as the percolation threshold $x_{C}$ when electrical contacts of $\mathrm{Fe}_{0.45} \mathrm{Co}_{0.45} \mathrm{Zr}_{0.10}$ MNPs begin to form percolating (highly-conductive) net in alumina matrix. TEM and HRTEM images reveal that granular films with $x<x_{C}$ contain crystalline metallic bcc $\alpha$-FeCo-based nanosized cores embedded in the amorphous $\mathrm{Al}_{2} \mathrm{O}_{3}$ matrix (Fig. 1a). A bcc structure of these MNPs (close to a pure reference $\mathrm{Fe}_{0.45} \mathrm{Co}_{0.45} \mathrm{Zr}_{0.10}$ alloy film) and their random orientation were also revealed by XRD and SAED measurements [6,7]. Fig. 1(b) shows that the alloy nanoparticles in set 1 films have tendency for agglomeration. Moreover, as XRD has shown, MNPs were highly disordered (probably due to the incorporation of the rest of oxygen atoms presented in the vacuum chamber) displaying an increase of lattice parameters as compared with that in pure FeCoZr film deposited at the same regime [6,7].

Granular $\left(\mathrm{Co}_{0.45} \mathrm{Fe}_{0.45} \mathrm{Zr}_{0.10}\right)_{x}\left(\mathrm{Al}_{2} \mathrm{O}_{3}\right)_{1-x}$ films sputtered in an atmosphere with added oxygen contain FeCo-based MNPs with 'metallic core-oxide shell' structure (Fig. 1b and c). Formation of such a structure, composed of crystalline metallic bcc $\alpha$-FeCobased nanosized "cores" encapsulated in FeCo-based oxide "shell" and all embedded in the amorphous alumina, was revealed by TEM and HRTEM [6,7]. EXAFS and XANES of set 2 samples exhibited almost full oxidation of iron, while cobalt only was found to be oxidized partially, by the periphery of MNPs. In strong correlation with the Mossbauer spectroscopy as well as with the results of electron- and X-ray diffraction this shows that for $x \leqslant 0.56$ the metallic "core" constitutes bcc FeCo solid solution, possibly enriched with $\mathrm{Co}$, while oxide "shell" mainly consists of mixed Ferich oxides. This resulted in the conservation of superparamagnetic state of MNPs up to $x=0.57$ where $\sigma(x)$ approaches maximum in Fig. 2(a). Moreover, as was shown in [9-11], addition of oxygen to the chamber suppressed the tendencies to the agglomeration of MNPs and stabilizing their sizes as opposed to that observed in the films of set 1 .

Fig. 2 shows the relationship of the measured conductivity $\sigma$ versus concentration $x$ of the metallic fraction $\left(\mathrm{Fe}_{0.45} \mathrm{Co}_{0.45} \mathrm{Zr}_{0.10}\right.$ alloy) in the studied films. Fig. 2(a) shows that $\sigma(x)$ curves, measured for set 1 samples at $300 \mathrm{~K}$, display monotonous, close to sigmoid-like behavior with inflection point that is characteristic for percolating systems. In the clearest form this is seen in Insert in Fig. 2(a), where 2nd derivative $\sigma^{\prime \prime}=d^{2} / d x^{2}$ are presented (this was derived by graphic differentiation). The figure shows that the $\sigma^{\prime \prime}(x)$ curve exhibiting a maximum at the concentrations $x_{\max }$ range of 0.48 and 0.51 . Position of $x_{\max }$ lies a little higher than the percolation threshold $x_{\mathrm{C}} \approx 0.43-0.45$, determined by Mössbauer and magnetization experiments [3,6,7]. Comparison of the $\sigma^{\prime \prime}(x)$ and $\sigma(x)$ curves allows separating $\sigma(x)$ behavior/progress in the nanocomposites of set 1-3 characteristic parts. Moreover, for region $A$ smooth $\sigma(x)$ increase with $x$ is observed up to the kink in its progress at $x \sim 0.45$ in Fig. 2(a). In the intermediate region B with 0.57 at.\% $<x<0.67$ curve $\sigma(x)$ fits with the highest rate of $\sigma$ increase with $x$ and $\sigma^{\prime \prime}(x)$ has linear behavior with higher slope than in region $A$. Note also that this part $B$ represents the range of compositions where samples of set 1 had the pronounced granular SEM images (see, Fig. 1a). When $x$ reaches the values of the order of $0.67, \sigma(x)$ curve extends to saturation (to $x=1.00$ ) whereas $\sigma^{\prime \prime}$ falls down due to agglomeration of MNPs and formation of metallic percolation net.

The $\sigma(x)$ dependence for set 2 films deposited in $\mathrm{Ar}$ with addition of oxygen did not have sigmoid-like shape (see, Fig. 2b).
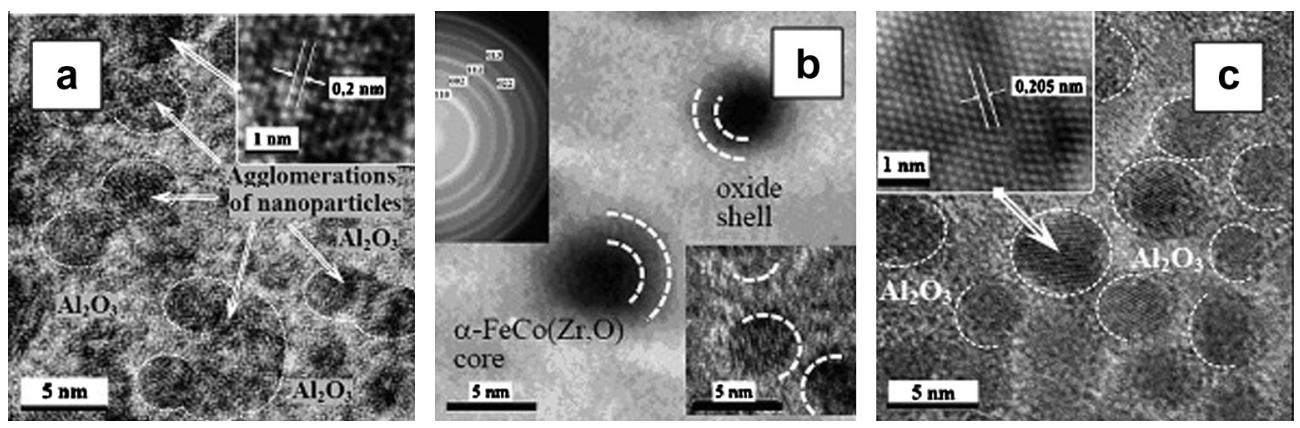

Fig. 1. HRTEM and TEM images of set 1 film with $x=0.42(a)$ and set 2 with $x=0.36(b)$ and $x=0.56(c)$. 

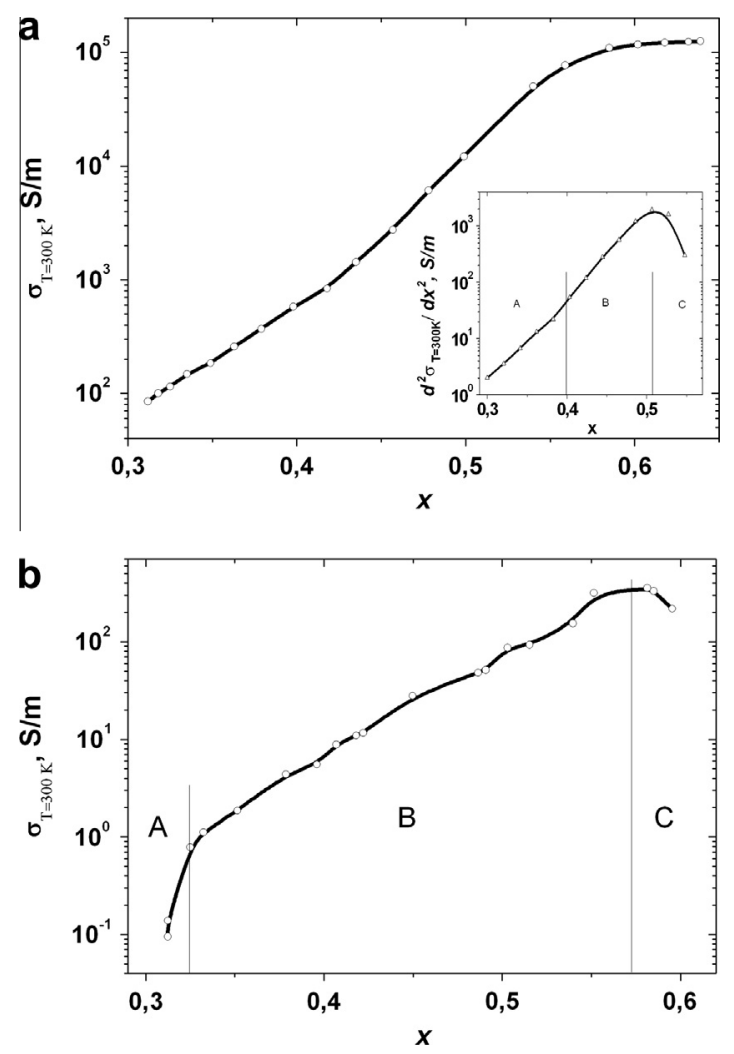

Fig. 2. Dependences of DC conductivity $(T=300 \mathrm{~K})$ on metal-to-dielectric ratio $x$ for set $1(a)$ and set $2(b)$ films. Insert: $\sigma^{\prime \prime}(x)$ dependences are presented.

Moreover the values of conductivity are app. 3 orders lower and that is related to the formation of FeCo-oxide "shells" shown in Fig. 1(b). The $\sigma(x)$ progress in set 2 nanocomposites also can be divided into 3 characteristic parts but these parts are determined by the progress of selected oxidation of MNPs during the deposition procedure. Moreover, as was proved in [7], this oxidation was enhanced with $x$ increase.

Comparing the obtained $\sigma(x)$ curves for the samples, belonging to different regions $A, B$ and $C$ in Figs. 2 and 3, on carrier transport mechanisms of the studied samples determining the $\sigma(T)$ dependences in Fig. 3. The experimental curves 1-6 in Fig. 3(a), plotted in Arrhenius scale, show that the samples of set 1 with $x<x_{\max }$ $\approx(0.48-0.51)$ exhibited exponential-like character of $\sigma(T)$ dependences with the change (lowering) of activation energy as temperature decreases down to $2 \mathrm{~K}$. Such behavior means that the set 1 samples from regions $A$ and $B$ lie on dielectric side of IMT and indicate hopping mechanism of conductance. The $\sigma(T)$ dependences for the samples of $C$ region (curves 7 in Fig. 3a) exhibited practically zero values of $(\mathrm{d} \sigma / \mathrm{d} T)$, that denotes the transition of set 1 films to the state close to metallic one (for detailed study of this behavior see in $[12,13])$.

Temperature dependences of DC conductivity of set 2 samples, presented in Fig. 3(b), displayed $\sigma(T)$ dependences with $(\mathrm{d} \sigma / \mathrm{d} T)>0$ for all compositions studied. Note also that even beyond the $x_{\max }-$ $\approx 0.57$ (in region $C$ in Fig. 2 b) no observed transition to metallic conductivity with power-like $\sigma(T)$ dependences (as mentioned above for set 1 films and in [12]). This indicates that the concentration $x_{\max }$, where $\sigma(x)$ curve exhibits maximum, can be considered as the concentration when oxidized FeCo-based MNPs are (touching) in contact with each other and form continuous highlyconductive net in the region $C$ in Fig. 2(b) (see, also [13]).

To understand the nature of activation laws of $\sigma(T)$ dependences for the samples of sets 1 and 2 in Fig. 3, these curves were re-plotted in Mott scales in accordance with the known relation
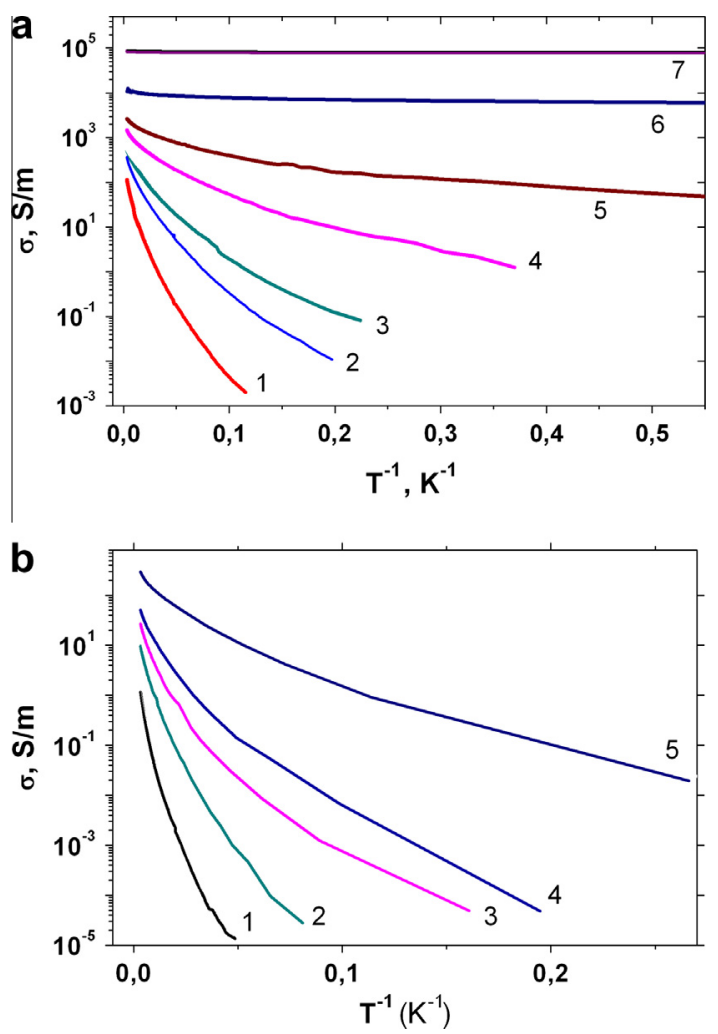

Fig. 3. Dependences of DC conductivity on temperature (in Arhenius scale) for the samples of set 1 (a) for $x=0.325$ (1), 0.380 (2), 0.398 (3), 0.440 (4), 0.457 (5), 0.496 (6), 0.560 (7) and of set 2 (b) with $x=0.33$ (1), 0.41 (2), 0.45 (3), 0.50 (4), 0.62 (5).

$\sigma(T)=\sigma_{o} \exp \left[-\left(\frac{T_{o}}{T}\right)^{-n}\right]$

for Variable Range Hopping (VRH) conductance (see, Fig. 4). Hear $\rho_{0}$ and $T_{0}$ are characteristic parameters of hopping models. The exponent $n$ in (1) depends on VRH regime: $n=0.25$ for Mott mechanism [14] and $n=0.50$ for Shklovski-Efros model [15].

The experiments of this paper have shown that (see, Fig. 4), for the studied composites of set 1 , being on dielectric side of IMT, Mott law was observed at temperatures higher than $110-120 \mathrm{~K}$ and changed to the Shklovski-Efros law, describing the hopping transport of the charge carriers at the Coulomb gap in the density of localized states, as temperature decreased.

The mentioned above also indicates that the concentration $x_{\max }$, where $\sigma^{\prime \prime}(x)$ curves for set 1 films exhibit maxima, can be considered as the percolation threshold. Therefore, behavior of $\sigma(T)$ in region $C$ (curve 7 in Fig. 3a) can be attributed to the carrier transport along with the percolating net of FeCoZr MNPs which is fully completed in this region of $x$. On the other side, the shift of $x_{\max }$ to higher concentrations as compared with $x_{C}$ values (0.43-0.45) observed in [6,7] should be noted. The value of $x_{\max }$ is close to 0.5 and that corresponds to 3D model of percolation for binary composites metal-insulator [8]. This shift and practically zero values of $(\mathrm{d} \sigma / \mathrm{d} T)$ can be attributed to the highly disordered state of metallic MNPs due to their enrichment by the rest oxygen as mentioned above.

Fig. 5 shows that the $\sigma(T)$ relationship with $T^{-0.5}$ as plotted on Mott scale for the samples of set 2. As oppose to set 1 films, no crossover from Mott to Shklovski-Efros law was observed as temperature decreased. Moreover, as is seen, in all set 2 nanocomposites, deposited in mixed $\mathrm{Ar}+\mathrm{O}_{2}$ atmosphere, $\sigma(T)$ display only Shklovski-Efros VRH regime of carrier transport which dominated at temperatures lower than $150 \mathrm{~K}$ down to $2 \mathrm{~K}$. The observed $\sigma(x$, $T$ ) dependences for set 2 films can be attributed to the formation 
a

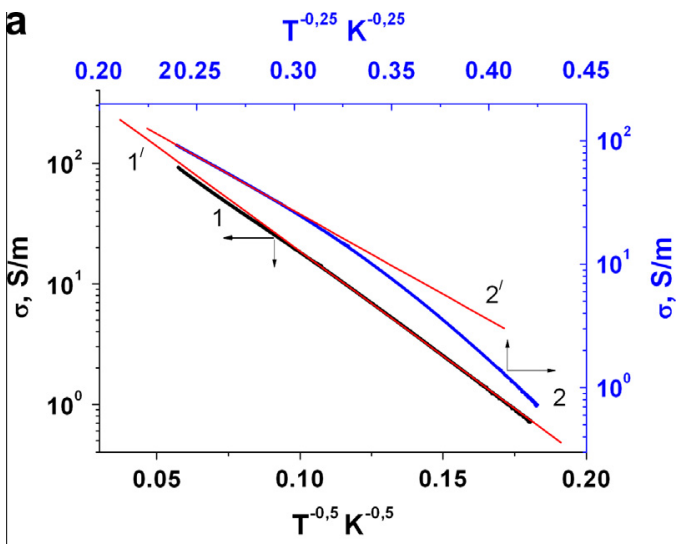

b

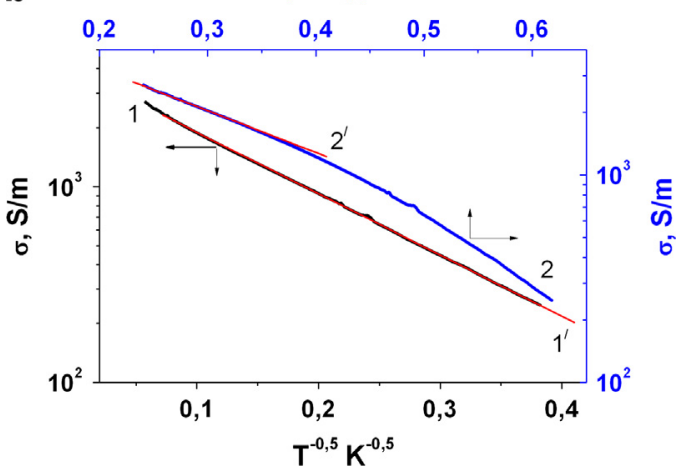

Fig. 4. Temperature dependences of conductivity $\sigma(T)$ for the samples of set 1 with $x=0.312(a)$ and $0.457(b)$ plotted in Mott scale with the exponent $n=0.5$ (curves 1 and $1^{\prime}$ ) and $n=0.25$ (curves 2 and $2^{\prime}$ ) using Eq. (1). 1, 2 - experimental data, $1^{\prime}, 2^{\prime}-$ linear approximations $\ln \rho-T^{-n}$ with $n=0.5$ and $n=0.25$ correspondingly.

of FeCo-based oxide "shells" around metallic alloy MNPs due to the addition of oxygen in vacuum chamber during deposition procedure.

\section{Resume}

It was shown that the temperature dependences of the DC conductivity $\sigma(T)$ in the $\left(\mathrm{Co}_{0.45} \mathrm{Fe}_{0.45} \mathrm{Zr}_{0.10}\right)_{x}\left(\mathrm{Al}_{2} \mathrm{O}_{3}\right)_{1-x}$ nanocomposites of set 1, deposited in $\mathrm{Ar}$ atmosphere and being on dielectric side of IMT, displayed a crossover from Mott-like to Shklovski-Efros VRH regime of carrier transport which occurred at temperatures about $100-120 \mathrm{~K}$. The observed shift of the percolation threshold to higher concentrations of metallic fraction from $\sigma(x, T)$ dependences, that follows from [6,7], can be attributed to the disordering of metallic alloy nanoparticles due to the incorporation of the rest oxygen in the vacuum chamber during the deposition procedure.

The temperature dependences of DC conductivity $\sigma(T)$ in the nanocomposites, deposited in mixed $\mathrm{Ar}+\mathrm{O}_{2}$ atmosphere, displayed only Shklovski-Efros VRH regime which occurred at temperatures lower than $150 \mathrm{~K}$ down to $2 \mathrm{~K}$ for all studied samples. The observed behavior of the $\sigma(x, T)$ dependences for such samples can be attributed to the formation of FeCo-based oxide "shells" around metallic alloy nanoparticles due to the addition of oxygen in the vacuum chamber during deposition procedure [3,6,7].

\section{Acknowledgments}

The work was partially supported by the VISBY Program of the Swedish Institute, Belarusian State Sub-Programme "Crystalline and Molecular Structures" by Contract 2.4 .12 and a research
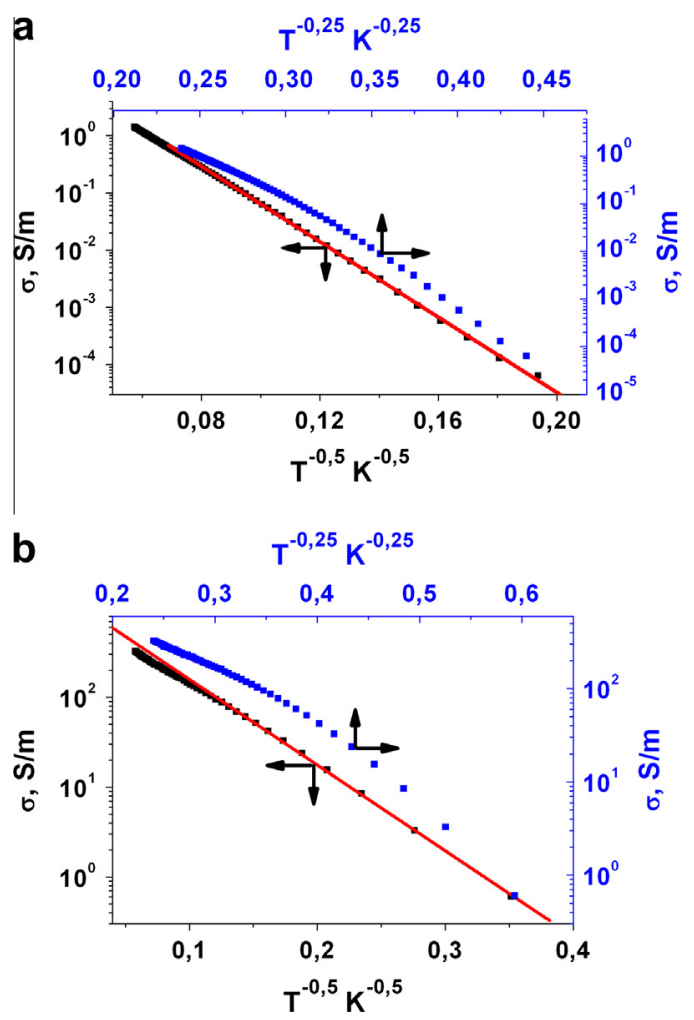

Fig. 5. Temperature dependences of conductivity $\sigma(T)$ for the samples of set 2 with $x=0.366(a)$ and $0.615(b)$ plotted in Mott scale with the exponents $n=0.5$ and $n=0.25$ using Eq. (1). Points are experimental data, straight lines are linear approximations $\ln \sigma-T^{-0.5}$.

project No IP2012 026572 within the Iuventus Plus program of Polish Ministry of Science and Higher Education in the years of 20132015.

\section{References}

[1] Y. Imry, in: W.P. Kirk, M.A. Reed (Eds.), Nanostructures and Mesoscopic Systems, Academic, New York, 1992, p. 11.

[2] G. Timp, Nanotechnology, Springer, New York, 1999.

[3] J. Fedotova, T.N. Koltunowicz, P. Zhukowski, in: P. Zhukowski (Ed.), Transport ładunków i właściwości strukturalne wybranych nanokompozytyw metaldielektryk, Politechnika Lubelska, Lublin, 2012, p. 173.

[4] P. Żukowski, T. Kołtunowicz, J. Partyka, Yu.A. Fedotova, A.V. Larkin, Vacuum 83 (Supplement 1) (2009) S275-S279.

[5] P. Żukowski, T. Kołtunowicz, J. Partyka, Yu.A. Fedotova, A.V. Larkin, Vacuum 83 (Supplement 1) (2009) S280-S283.

[6] J. Fedotova, $\mathrm{FeCoZr}-\mathrm{Al}_{2} \mathrm{O}_{3}$ granular nanocomposite films with tailored structural electric magnetotransport and magnetic properties, in: B. Aktas, F. Mikailov (Eds.), Advances in Nanoscale Magnetism, vol. 122, Springer Proceedings in Physics, Berlin, 2008, pp. 231-267.

[7] J. Fedotova, J. Przewoznik, Cz. Kapusta, M. Milosavljević, J.V. Kasiuk, J. Zukrowski, M. Sikora, A.A. Maximenko, D. Szepietowska, K.P. Homewood, J. Phys. D Appl. Phys. 44 (2011). 495001-1-495001-12.

[8] G. Grimmet, Percolation, second ed., Springer-Verlag, Berlin, 1999.

[9] P. Glatzel, M. Sikora, S.G. Eeckhout, O.V. Safonova, G. Smolentsev, G. Pirngruber, J.A. van Bokhoven, J.D. Grunewaldt, M. Tromp, AIP Conf. Proc. 879 (2007) 1731-1734.

[10] T.N. Kołtunowicz, P. Zhukowski, V.V. Fedotova, A.M. Saad, A.V. Larkin, Acta Phys. Pol., A 120 (1) (2011) 35-38.

[11] T.N. Kołtunowicz, P. Zhukowski, V.V. Fedotova, A.M. Saad, A.K. Fedotov, Acta Phys. Pol., A 120 (1) (2011) 39-42.

[12] A.M. Saad, A.K. Fedotov, J.A. Fedotova, I.A. Svito, B.V. Andrievsky, Yu.E. Kalinin, V.V. Fedotova, V. Malyutina-Bronskaya, A.A. Patryn, A.V. Mazanik, A.V. Sitnikov, Phys. Status Solidi C 3 (2006) 1283-1290.

[13] A. Saad, A. Mazanik, Y. Kalinin, J. Fedotova, A. Fedotov, S. Wrotek, A. Sitnikov, I. Svito, Rev. Adv. Mater. Sci. 8 (2004) 152-157.

[14] N.F. Mott, E.A. Davis, Electron Process in Non-Crystalline Materials, Claredon Press, Oxford, 1979.

[15] A.L. Efros, B.I. Shklovskii, Phys. Status Solidi B 76 (1976) 475-485. 